\title{
Thermal Properties of Mg-Al/AIN Composites Fabricated by Powder Metallurgy
}

\author{
Jie Chen ${ }^{1} \cdot$ Chong-Gao Bao ${ }^{2} \cdot$ Zhi-Wei Liu $^{2} \cdot$ Ben-Shuang Sun ${ }^{1} \cdot$ Yong-Chun Shu ${ }^{1} \cdot$ Qing-Kui Li $^{1}$
}

Received: 14 July 2017 / Revised: 15 August 2017 / Published online: 13 December 2017

(C) The Chinese Society for Metals and Springer-Verlag GmbH Germany, part of Springer Nature 2017

\begin{abstract}
Magnesium matrix composites reinforced with AlN particles were fabricated by the powder metallurgy technique. Different mixing methods were used in this study to control the distribution of AlN particles. The microstructure, thermal diffusivity and thermal expansion of the $\mathrm{Mg}-\mathrm{Al} / \mathrm{AlN}$ composites using different mixing methods were investigated. The results showed that the intergranular and intragranular distributions of AIN particles were obtained, respectively, by controlling the mixing methods. The composite with intragranular particles exhibited lower thermal diffusivity because of the existences of more interfaces, defects and grain boundaries, which acted as scattering centers and reduced the mean free path of electrons and phonons. The existence of AlN particles lowered the coefficient of thermal expansion (CTE) and enhanced the dimensional stability of the composites. And the use of the improved mixing method further reduced the CTE of $\mathrm{Mg}-\mathrm{Al} / \mathrm{AlN}$ composites.
\end{abstract}

Keywords Magnesium matrix composite $\cdot$ Microstructure $\cdot$ Thermal diffusivity $\cdot$ Thermal expansion · Mixing

\section{Introduction}

The light weight metals and composites have developed rapidly in recent years in order to reduce the fuel consumption and the greenhouse gas emission [1]. Among all structural materials, magnesium alloy as the lightest metal material has great potential to extend its application, especially in aerospace and automobile industries [2,3]. The obstacles for the application of $\mathrm{Mg}$ metal include its low strength, poor ductility and low wear resistance. However, the shortages of $\mathrm{Mg}$ alloy can be improved by the use of reinforced particles, such as the addition of $\mathrm{SiC}$

Available online at http://link.springer.com/journal/40195

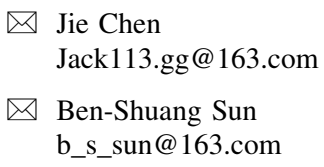

1 Henan Province Industrial Technology Research Institute of Resources and Materials, Zhengzhou University, Zhengzhou 450001, China

2 State Key Laboratory for Mechanical Behavior of Materials, School of Materials Science and Engineering, Xi' an Jiaotong University, Xi' an 710049, China
[4], $\mathrm{B}_{4} \mathrm{C}$ [5], $\mathrm{TiB}_{2}$ [6], etc., to produce magnesium matrix composites with enhanced properties.

AlN ceramic has excellent thermal properties besides its good mechanical properties, such as low CTE and good thermal conductivity [7]. Thus, the mechanical properties and thermal properties of $\mathrm{Mg}$ metal matrix can be improved simultaneously by the use of AlN, which gives an origin to an attractive composite for electronic packaging industry [8]. The mechanical properties of AlN particles reinforced magnesium matrix composites have been studied in detail [9-11]. It was reported that the addition of AlN particles improved effectively the mechanical properties of $\mathrm{Mg}$ metal matrix.

Thermal properties, including thermal expansion, thermal diffusivity and thermal conductivity, play important roles in the performance of metal matrix composites (MMCs) [12]. The thermal expansion can be quantitatively described by the CTE [13], which is usually considered as a necessary parameter in the applications requiring stringent dimensional stability and exceptional resistance to distortion from thermal or thermomechanical loads, for example, in aerospace, ground transportation, thermal management, precision devices and propulsion systems [14, 15]. Meanwhile, the thermal conductivity can guide the application of the composites when the materials are employed at 
environment with changed temperatures. For example, high thermal conductivity ensures a uniform temperature distribution which reduces thermally induced stresses, thereby prolonging the service life of materials [16]. However, no attempt is made so far to study the thermal properties of $\mathrm{Mg}-\mathrm{Al} / \mathrm{AlN}$ composites in detail.

In powder-processed material, the powders state after mixing can effectively affect the final reinforcement distribution in metal matrix composites [17, 18]. It is well known that the properties of the MMCs are significantly influenced by the reinforcement distribution [19]. However, the effect of AlN particle distribution on the thermal properties of $\mathrm{Mg}-\mathrm{Al} / \mathrm{AlN}$ composites is still unclear. So it is necessary to study the issue. In this study, the intergranular and intragranular distributions of AlN particles in the $\mathrm{Mg}-\mathrm{Al} / \mathrm{AlN}$ composites by controlling the mixing methods were obtained. The thermal properties including the thermal diffusivity and the thermal expansion were investigated for the $\mathrm{Mg}-\mathrm{Al} / \mathrm{AlN}$ composites. The influence of AlN particles distribution on the thermal properties in the composites was discussed and analyzed.

\section{Experimental}

Powder metallurgy (P/M) technology was used in this study for preparing the composites. The conventional mixing method and improved mixing method were used, respectively, in order to produce intergranular and intragranular particle distribution in the final composites. The preparation process of the $\mathrm{Mg}-\mathrm{Al} / \mathrm{AlN}$ composites is shown in Fig. 1. Commercial powders of $\mathrm{Mg}$ (>99\% purity, $75 \mu \mathrm{m}$, Kemio Chemical Reagents Co., Ltd, China), Al (> 99\% purity, $10 \mu \mathrm{m}$, Titd Metal Materials Co., Ltd, China) and AlN (> 99\% purity, 1-3 $\mu \mathrm{m}$, Eno High-Tech Material Development Co., Ltd, China) were selected as the raw materials. Powder mixture with designed composition of $5 \mathrm{wt} \% \mathrm{AlN}$, and the balances were $\mathrm{Mg}$ and $\mathrm{Al}$ (the mass ratio of $\mathrm{Mg}$ to $\mathrm{Al}$ was about 91:9). In the conventional mixing method, all raw materials were mechanical milled at $70-100 \mathrm{rpm}$ for over $24 \mathrm{~h}$ by a GLM roller mill
(Xiangtan city instruments Co., Ltd, China), and the detailed process was described in Ref. [7]. The improved mixing method was used to obtain the intragranular distribution of AlN particles. Firstly, the mixture powders of AlN and Mg were milled in a QM-3SP4 planetary ball mill under an argon atmosphere for $15 \mathrm{~h}$ at the rotation speed of $390 \mathrm{rpm}$. Secondly, the matrix alloy particles of $\mathrm{Mg}$ and $\mathrm{Al}$ were milled for $20 \mathrm{~h}$ under the same experimental parameter. Then, the milled reinforcement particles and matrix alloy particles were blended uniformly. The detailed process of improved mixing method was described in Ref. [19]. The difference between the two mixing method is that multi-step independent high-energy ball milling was used in the improved mixing method. But for the conventional mixing method, all the raw materials were mixed by onestep low-speed ball milling.

The following fabrication processes were the same for both conventional powders and improved powders. The powders were hot-pressing-sintered at $570{ }^{\circ} \mathrm{C}$ for $1 \mathrm{~h}$ under argon atmosphere using 50-mm diameter dies. The sintered billets were then extruded at $330{ }^{\circ} \mathrm{C}$ to produce a bar with a diameter of $14 \mathrm{~mm}$, and the extrusion ratio was about 12.76. In addition, the commercial Mg-Al-based alloy (the mass ratio of $\mathrm{Mg}$ to $\mathrm{Al}$ was about 91:9, extruded bar, Dongguan Hongdi Metal Co., Ltd, China) was selected as the comparative sample, and the thermal properties of both commercial $\mathrm{Mg}-\mathrm{Al}$ alloy and $\mathrm{Mg}-\mathrm{Al} / \mathrm{AlN}$ composites were examined.

The microstructures of the specimens were observed using a scanning electron microscope (SEM, VEGAI XMUINCA) equipped with energy-dispersive X-ray spectrometry (EDS) system. The phase analysis of the specimens was conducted by X-ray diffraction (XRD, X'Pert PRO) with $\mathrm{Cu} K_{\alpha}$ radiation. The thermal diffusivity and specific heat capacity of the samples were measured by using laser flash apparatus (Netzsch LFA447) at 25$275{ }^{\circ} \mathrm{C}$. The specimens were cut from extruded rods perpendicular to the extrusion direction in the form of disks with a size of $\Phi 12.7 \mathrm{~mm} \times 2.5 \mathrm{~mm}$. The step of testing temperatures was $50{ }^{\circ} \mathrm{C}$, and at least three shots were emitted at each testing temperature. Prior to the

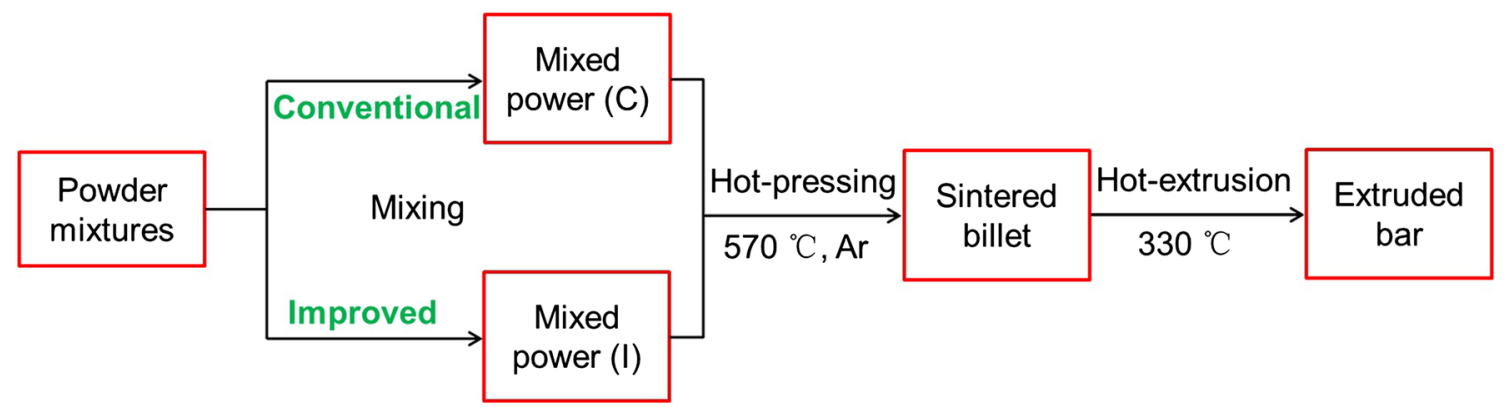

Fig. 1 Preparation process of $\mathrm{Mg}-\mathrm{Al} / \mathrm{AlN}$ composites 
measurement, the surface of the specimens was blackened by carbon coating in order to improve the absorption of the light pulse. The thermal conductivity $\lambda(\mathrm{W} /(\mathrm{m} \mathrm{K}))$ was calculated using the following relation $[20,21]$ :

$\lambda=\alpha \cdot \rho \cdot C_{\mathrm{p}}$.

where $\alpha$ is the thermal diffusivity $\left(\mathrm{mm}^{2} / \mathrm{s}\right), \rho$ is the density $\left(\mathrm{g} / \mathrm{cm}^{3}\right)$, and $C_{\mathrm{p}}$ is the specific heat capacity $(\mathrm{J} /(\mathrm{g} \mathrm{K}))$. The density was measured using the Archimedes method with absolute ethyl alcohol as the immersion media. The thermal expansion coefficient of the samples was measured in nitrogen atmosphere using the L75VS1400C dilatometer from 75 to $450{ }^{\circ} \mathrm{C}$ at heating rate of $5{ }^{\circ} \mathrm{C} / \mathrm{min}$. Specimens for the test were prepared with a diameter of $6 \mathrm{~mm}$ and a height of $20 \mathrm{~mm}$.

\section{Results and Discussion}

\subsection{Microstructure}

The microstructures of the $\mathrm{Mg}-\mathrm{Al} / \mathrm{AlN}$ composites using different mixing methods are shown in Fig. 2. Figure 2a, b shows the microstructures of $\mathrm{Mg}-\mathrm{Al} / \mathrm{AlN}$ composites using the conventional mixing method, which are perpendicular and parallel to the extrusion direction, respectively. It could be observed that the composite mainly consisted of three parts: coarse-grained matrix, ultrafine-grained matrix and ceramic reinforcement. AlN particles were aligned in the longitudinal direction due to the plastic flow of the matrix metal. And few particles existed in the matrix between extruded lines as pointed by the rectangular box in Fig. $2 b$. It was obvious that the reinforcement particles were mainly distributed along the grain boundary, and the presence of AlN particles was scarce in the interior of grains. Meanwhile, it could be seen that some particles were agglomerated in local areas of $\mathrm{Mg}$ matrix due to the limited grain boundaries space. Figure $2 \mathrm{c}$, d shows the microstructures of $\mathrm{Mg}-\mathrm{Al} / \mathrm{AlN}$ composites using the improved mixing method. No obvious coarse-grained matrix was found, and the average grain size of the composite reduced greatly after using the improved mixing method. And a lot of AlN particles existed in the matrix between extruded lines in the longitudinal direction. It was obvious that the AlN reinforcement particles distributed homogeneously in $\mathrm{Mg}$ matrix, and most of that were located inside the grain of $\mathrm{Mg}$ matrix after using the improved mixing method. The optical micrographs of $\mathrm{Mg}-\mathrm{Al} / \mathrm{AlN}$ composites using different mixing methods further confirmed the distribution of AlN particles, as shown in Fig. 3. In addition, it should be noted that the use of different mixing methods did not cause the change in the distribution of $\mathrm{Mg}_{17} \mathrm{Al}_{12}$ phase. The detailed description about $\mathrm{Mg}_{17} \mathrm{Al}_{12}$ phase in the $\mathrm{Mg}-\mathrm{Al} /$ AlN composites was published in Ref. [22].
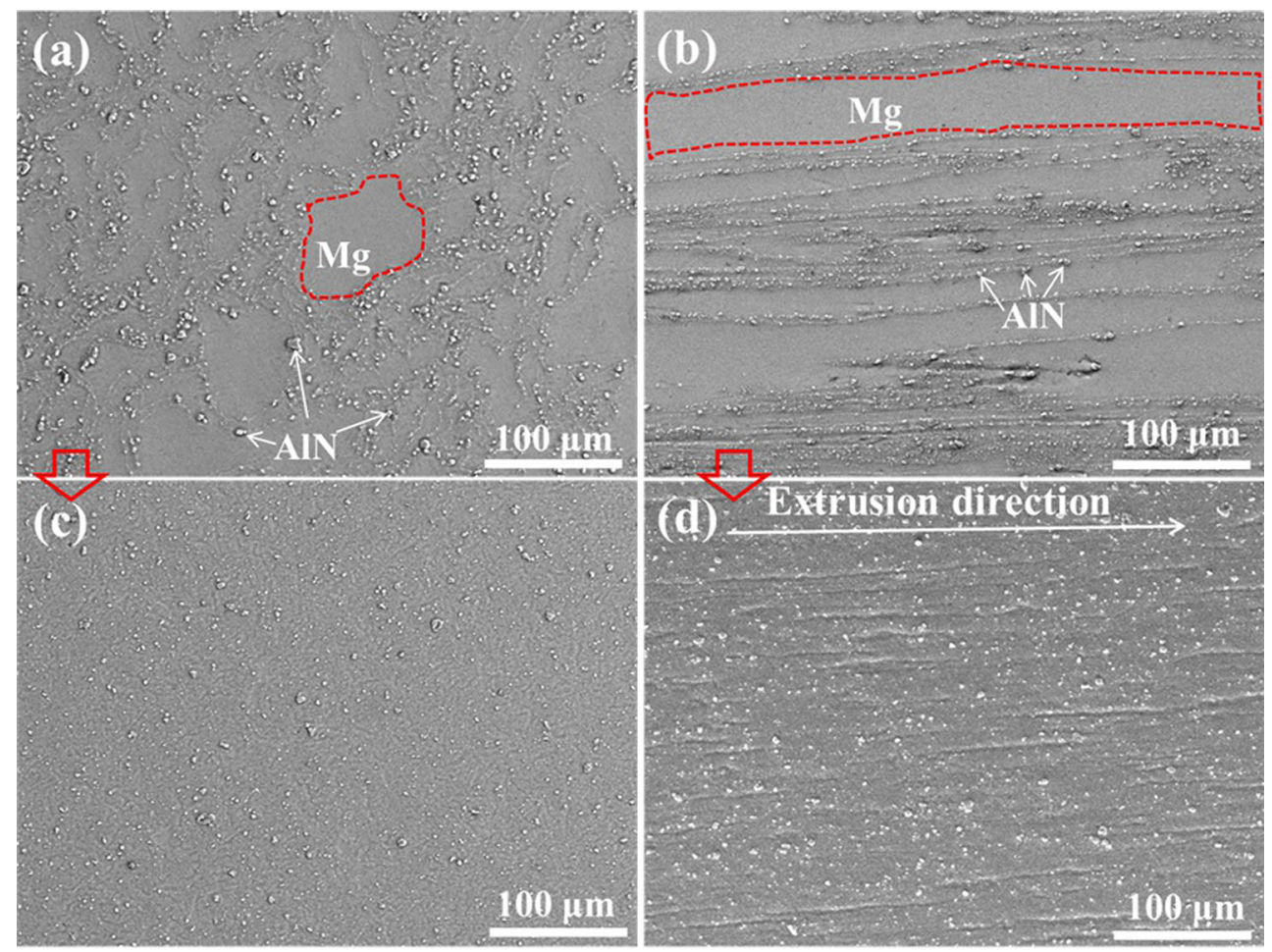

Fig. 2 Microstructures of Mg-Al/AlN composites in cross section $\mathbf{a}, \mathbf{c}$ and longitudinal section $\mathbf{b}$, $\mathbf{d}$ by using conventional $\mathbf{a}, \mathbf{b}$, improved $\mathbf{c}$, d mixing method 


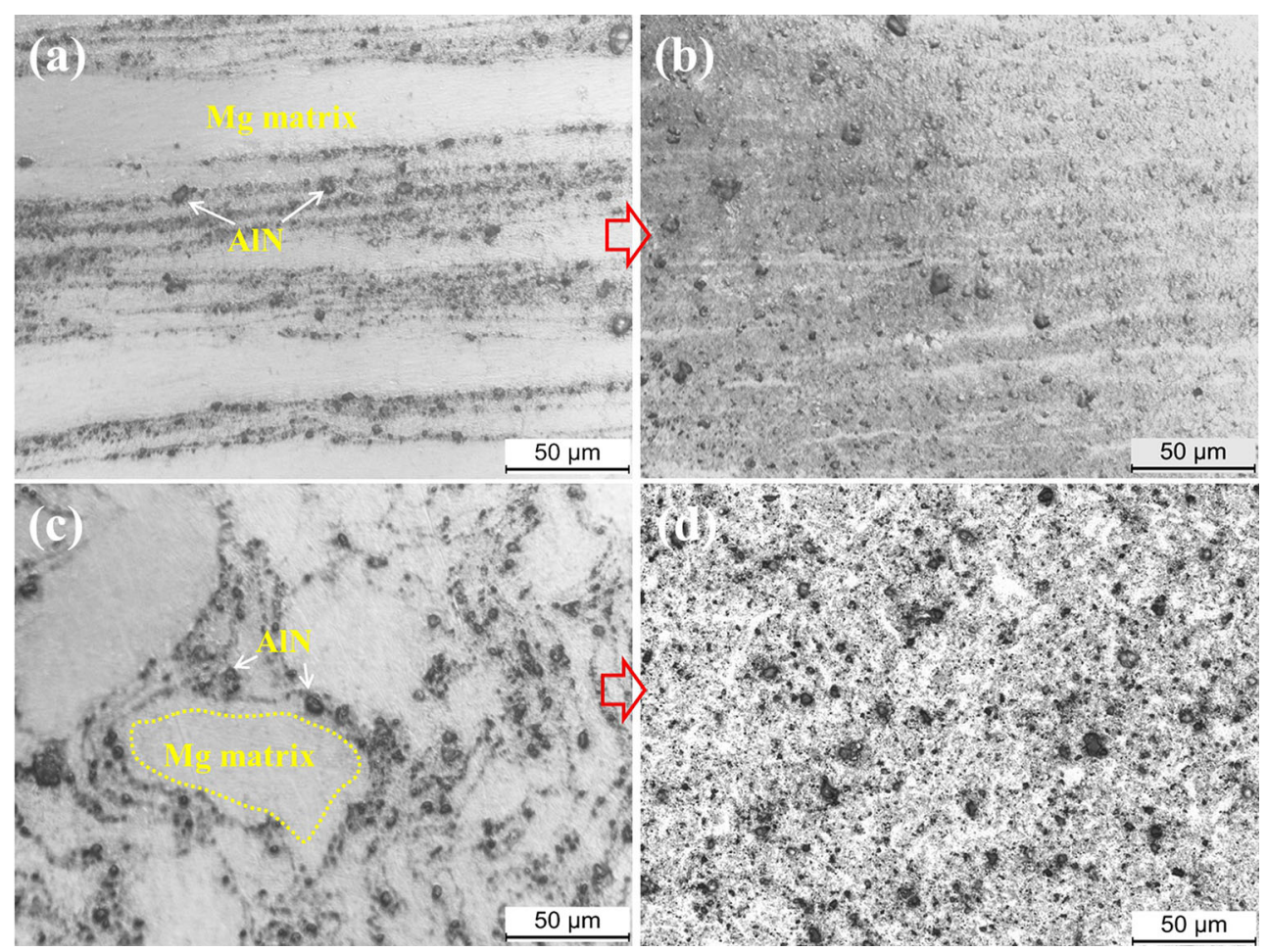

Fig. 3 Optical micrographs of $\mathrm{Mg}-\mathrm{Al} / \mathrm{AlN}$ composites in cross section $\mathbf{a}, \mathbf{c}$ and longitudinal section $\mathbf{b}, \mathbf{d}$ by using conventional $\mathbf{a}, \mathbf{b}$, improved $\mathbf{c}$, d mixing method

Besides, the fine equiaxed grains can be observed in the $\mathrm{Mg}-\mathrm{Al} / \mathrm{AlN}$ composites as pointed out by the arrows in Fig. 4, which indicates that dynamic recrystallization (DRX) occurred during the preparation process. It could be found that the recrystallization grains in the composite using the improved mixing method were smaller than those using the conventional mixing method. The DRX nucleation mechanism was a typical particle stimulating nucleation (PSN) mechanism. DRX nucleation would be accelerated in the zones of AlN particles according to the PSN theory [23, 24], resulting in a much smaller grain size. The more dispersed the particles, the more the nucleation points. Thus, the recrystallization grains were smaller for the composite using the improved mixing method, due to the improvement in particles distribution.

The matrix grain was not only significantly refined by using the improved mixing method, but also the distribution of AlN particles was effectively improved. The intergranular and intragranular distributions of particles were obtained, respectively, by controlling the powder state before sintering. The intergranular particles were easily agglomerated, and the agglomeration will be more pronounced with increasing reinforcement content due to the limited grain boundaries space. However, the intragranular particles showed more uniform distribution in the $\mathrm{Mg}$ matrix because there was no such space limitation. In
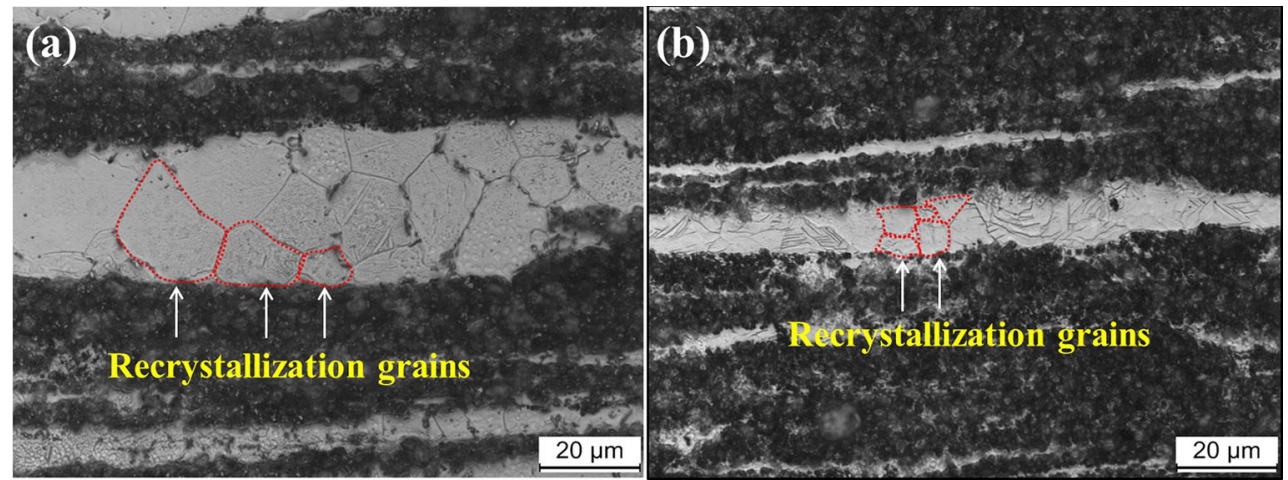

Fig. 4 Microstructures of recrystallization grains of $\mathrm{Mg}-\mathrm{Al} / \mathrm{AlN}$ composites using conventional $\mathbf{a}$, improved $\mathbf{b}$ mixing method 
addition, the microstructures of commercial $\mathrm{Mg}-\mathrm{Al}$ alloy are shown in Fig. 5a, b, which are perpendicular and parallel to the extrusion direction, respectively. It was obvious that the intermetallic compound particles were mainly distributed along the grain boundary of $\mathrm{Mg}$ matrix, and most of particles were located at the extruded-lines regions in the longitudinal direction. This means that the commercial $\mathrm{Mg}-\mathrm{Al}$ alloy had a similar particle distribution with the $\mathrm{Mg}-\mathrm{Al} / \mathrm{AlN}$ composite using the conventional mixing method.

\subsection{Thermal Diffusivity and Thermal Conductivity}

The temperature dependences of thermal diffusivity for the commercial $\mathrm{Mg}-\mathrm{Al}$ alloy and $\mathrm{Mg}-\mathrm{Al} / \mathrm{AlN}$ composites are shown in Fig. 6. It can be seen that the thermal diffusivity of commercial $\mathrm{Mg}-\mathrm{Al}$ increased with increasing temperature. The temperature dependence of thermal diffusivity of the $\mathrm{Mg}-\mathrm{Al} / \mathrm{AlN}$ composites using the conventional mixing method was similar to that of the commercial $\mathrm{Mg}-\mathrm{Al}$ alloy. It was found that the thermal diffusivity of the composite using the improved mixing method was insensitive to an increase in temperature. The increase rate with increasing temperature was smaller. Meanwhile, it was obvious that the composites with AlN particles had smaller values of thermal diffusivity than commercial $\mathrm{Mg}-\mathrm{Al}$ alloy, no matter which mixing method was applied. The $\mathrm{Mg}-\mathrm{Al} / \mathrm{AlN}$ composite with intragranular particles showed a smallest value of thermal diffusivity among the materials.

Thermal conductivity values were calculated using Eq. (1), and the results are shown in Fig. 7. Generally, the variation of thermal conductivity with temperature was similar to that of thermal diffusivity. The value of thermal conductivity was $34.8-41.9 \mathrm{~W} /(\mathrm{m} \mathrm{K})$ for $\mathrm{Mg}-\mathrm{Al} / \mathrm{AlN}$ composites at room temperature, which was smaller than that of commercial $\mathrm{Mg}-\mathrm{Al}$ alloy $(74.6 \mathrm{~W} /(\mathrm{m} \mathrm{K}))$.

Thermal conductivity was the intrinsic property of a material that indicates its ability to conduct heat [25]. Heat

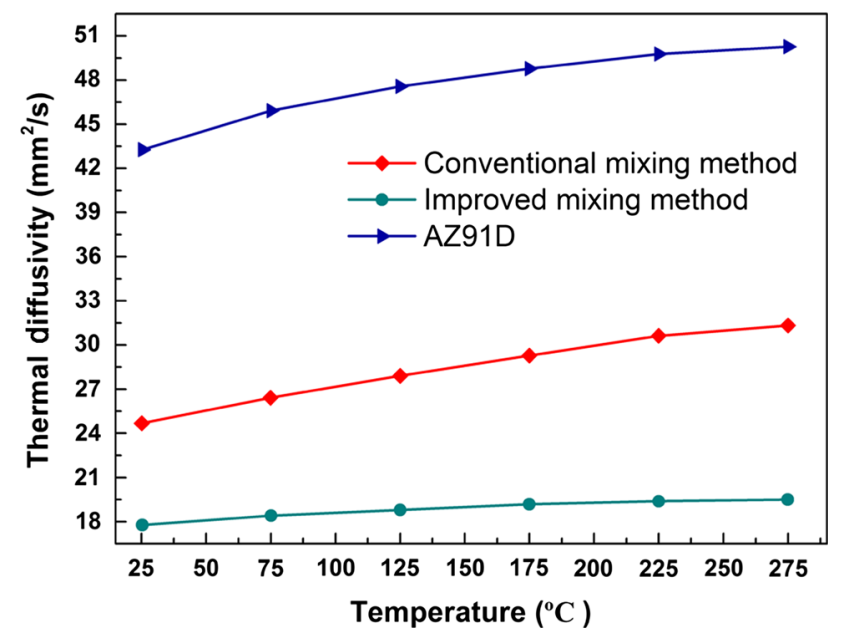

Fig. 6 Thermal diffusivities as a function of temperature for commercial $\mathrm{Mg}-\mathrm{Al}$ alloy and $\mathrm{Mg}-\mathrm{Al} / \mathrm{AlN}$ composites using different mixing methods

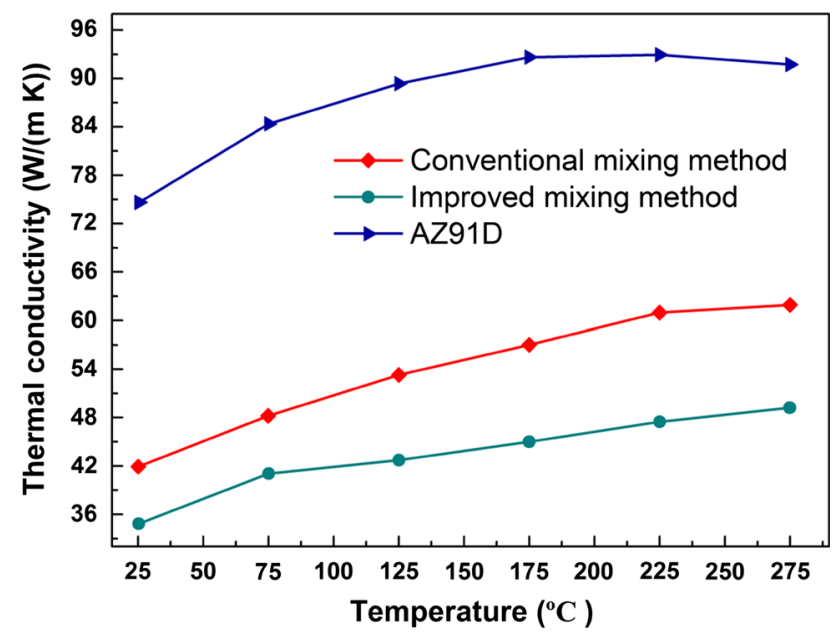

Fig. 7 Thermal conductivities as a function of temperature for commercial $\mathrm{Mg}-\mathrm{Al}$ alloy and $\mathrm{Mg}-\mathrm{Al} / \mathrm{AlN}$ composites using different mixing methods
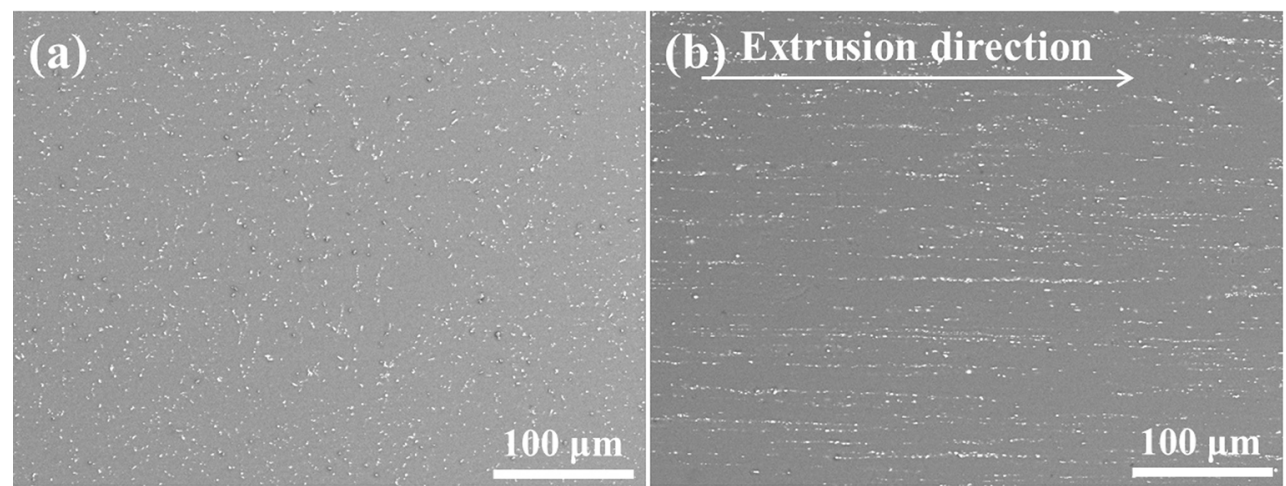

Fig. 5 Microstructures of commercial $\mathrm{Mg}-\mathrm{Al}$ alloy in cross section $\mathbf{a}$, longitudinal section $\mathbf{b}$ 
flows through solid metals by two transportations: lattice vibrational waves, which were called phonons, and free electrons [12]. The thermal conductivity can be described by the following equation [26]:

$\lambda=\frac{1}{3} c v l$.

where $\lambda$ is the thermal conductivity, $c$ is the heat capacity, $v$ is the average velocity, and $l$ is the mean free path. Combined with the relationship between thermal conductivity and thermal diffusivity (Eq. 1), it can be concluded that thermal diffusivity $(\alpha)$ was proportional to the mean free path $(l)$ of phonon and electron. The total mean free path was determined by the intrinsic properties as well as defects and boundaries presented in the material, and it can be described as follows [25, 27]:

$\frac{1}{l}=\frac{1}{l_{\mathrm{pe}}}+\frac{1}{l_{\mathrm{d}}}+\frac{1}{l_{\mathrm{b}}}$

where $l$ is the total mean free path, $l_{\mathrm{pe}}$ is the mean free path due to phonon or electron scattering, $l_{\mathrm{d}}$ is the mean free path due to defect scattering, and $l_{\mathrm{b}}$ is the mean free path due to boundary scattering. $l_{\mathrm{pe}}$ was related to intrinsic properties of materials and highly sensitive to temperature. Nevertheless, $l_{\mathrm{d}}$ and $l_{\mathrm{b}}$ were related to the microstructures of materials, such as grain boundaries, dislocation and pore.

As the temperature increased, electron and phonon were easily scattered by high-frequency lattice vibration, which caused the $l_{\mathrm{pe}}$ to decrease [12]. However, the average velocities of electron increased with temperature, and it became dominant to the thermal diffusivity [2]. As a result, the thermal diffusivity of the materials in this study generally increased with temperature. In addition, it should be noted that the phase compositions were not changed before and after measuring the thermal diffusivity for both the commercial $\mathrm{Mg}-\mathrm{Al}$ alloy and $\mathrm{Mg}-\mathrm{Al} / \mathrm{AlN}$ composites. Figure 8 shows the XRD patterns of commercial $\mathrm{Mg}-\mathrm{Al}$ alloy and $\mathrm{Mg}-\mathrm{Al} / \mathrm{AlN}$ composites before and after measuring the thermal diffusivity. It can be seen that the commercial $\mathrm{Mg}-\mathrm{Al}$ alloy mainly consisted of $\mathrm{Mg}, \mathrm{Mg}_{17-}$ $\mathrm{Al}_{12}$ and $\mathrm{Al}_{4} \mathrm{Ce}$ phases, and the $\mathrm{Mg}-\mathrm{Al} / \mathrm{AlN}$ composites mainly consisted of $\mathrm{Mg}, \mathrm{AlN}, \mathrm{MgO}$ and $\mathrm{Mg}_{17} \mathrm{Al}_{12}$ phases, no matter whether the thermal diffusivity measurements were taken. This suggests that the measurement of thermal diffusivity did not cause the formation of any new phase. Therefore, the effect of constitution change on the variation of thermal diffusivity with temperature was not considered in this investigation.

The slop of the temperature dependence of the thermal diffusivity was related to the intrinsic structure of the composites. For the commercial $\mathrm{Mg}-\mathrm{Al}$ alloy and $\mathrm{Mg}-\mathrm{Al} /$ AlN composite using the conventional mixing method, both the intermetallic compound and reinforcement particles were mainly distributed along the grain boundary of $\mathrm{Mg}$ matrix. The similar intrinsic structure resulted in the similar temperature dependence of thermal diffusivity. However, for the $\mathrm{Mg}-\mathrm{Al} / \mathrm{AlN}$ composite using the improved mixing method, reinforcement particles were mostly located inside the grain of matrix alloy. It was possible that the dispersed intragranular distribution of AlN particles improved the thermal stability of the composites, which led to a smaller slope of the temperature dependence of the thermal diffusivity. Hou et al. [28] prepared the short carbon fibers-reinforced magnesium matrix composites by the powder metallurgy technology. They also reported that the distribution of reinforcement had a great influence on the thermal conductivity of the composites.

For the smaller value of thermal diffusivity of $\mathrm{Mg}-\mathrm{Al} /$ $\mathrm{AlN}$ composites than commercial $\mathrm{Mg}-\mathrm{Al}$ alloy, there were two main reasons. On the one hand, the addition of AlN particles would produce a lot of AlN/Mg matrix interfaces and dislocations [11], which resulted in smaller mean free path $\left(l_{\mathrm{b}}\right.$ and $\left.l_{\mathrm{d}}\right)$ due to the scattering roles of boundary and defects to electrons and phonons. On the other hand, the rare earth element $\mathrm{Ce}$ was included in commercial $\mathrm{Mg}-\mathrm{Al}$ alloy (Fig. 8). The addition of Ce caused the increase in the
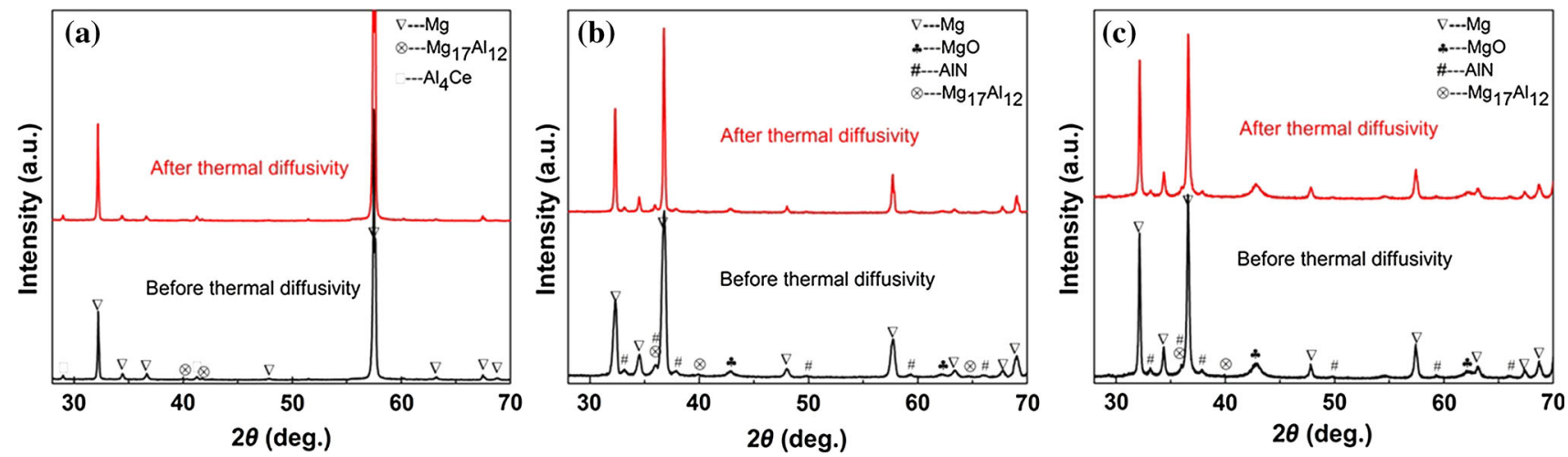

Fig. 8 XRD patterns before and after measuring thermal diffusivity: a commercial $\mathrm{Mg}-\mathrm{Al}$ alloy; $\mathbf{b} \mathrm{Mg}-\mathrm{Al} / \mathrm{AlN}$ composite using conventional mixing method; $\mathbf{c} \mathrm{Mg}-\mathrm{Al} / \mathrm{AlN}$ composite using improved mixing method 
thermal diffusivity due to the decrease in $\mathrm{Al}$ content in the solid solution of $\alpha-\mathrm{Mg}$ matrix for $\mathrm{Mg}-\mathrm{Al}$ alloy [29]. This was probably attributed to the small amount precipitates of $\mathrm{Al}_{4} \mathrm{Ce}$, which consumed $\mathrm{Al}$ solute atoms in the $\mathrm{Mg}$ matrix, so the lattice distortion was released and the scattering effect of the solutes on the electron and phonon transportation was largely depressed [16]. Therefore, the $\mathrm{Mg}-$ Al/AlN composites showed lower thermal diffusivity than commercial $\mathrm{Mg}-\mathrm{Al}$ alloy, due to the presence of $\mathrm{AlN} / \mathrm{Mg}$ interfaces and the absence of rare earth element $\mathrm{Ce}$.

The thermal diffusivity value of the $\mathrm{Mg}-\mathrm{Al} / \mathrm{AlN}$ composite using the improved mixing method was smaller than that of the composite using the conventional mixing method. First, the dispersed intragranular particles would produce more effective AlN/Mg interfaces than the concentrated AlN intergranular particles. The scattering effect of interfaces on the electron and phonon transportation was enhanced, which limited the mean free path of electrons and phonons. Second, the high-energy milling was used in the improved mixing method. Since the powder particles experienced severe plastic deformation in high-energy milling, a variety of crystal defects such as dislocations, vacancies and others were introduced [30]. These lattice defects would act as the scattering centers that block the free movement of electrons and phonons. Third, the average grain size of the composite was reduced greatly after using the improved mixing method. As a result, more grain boundaries were produced, which acted as scattering centers for electrons and phonons and limited the mean free path. Therefore, the composite with intragranular particle distribution exhibited lower thermal diffusivity.

\subsection{Thermal Expansion}

Figure 9 shows the temperature dependence of the relative elongation and the CTE for commercial $\mathrm{Mg}-\mathrm{Al}$ alloy and
$\mathrm{Mg}-\mathrm{Al} / \mathrm{AlN}$ composites using different mixing methods. The thermal expansion coefficient was calculated as follows [20]:

$\alpha^{\prime}=\frac{\mathrm{d} L}{L_{0} \mathrm{~d} T}$.

where $L_{0}$ is the original length of the specimen at room temperature, $L$ is the actual length of specimen at $T$, and $\mathrm{d} L$ is the elongation at the temperature interval of $\mathrm{d} T$. It can be found from Fig. 9a that the relative elongation of all samples increased with temperature. Since atoms in solids vibrated about their mean positions with amplitudes that increased with temperature, a material would expand when heated [15]. However, the degree of relative elongation was different for different materials tested in this study. It was evident from Fig. 9a that the relative elongations of composites were lower than that of the commercial $\mathrm{Mg}-\mathrm{Al}$ alloy within the tested temperature range, due to the resistance to matrix expansion in the composites provided by the AIN reinforcements with low CTE. The order of relative elongation from top to end was commercial $\mathrm{Mg}-$ $\mathrm{Al}$, composite using the conventional mixing method and composite using the improved mixing method. The relative elongation of the composite using the improved mixing method was smaller than that of the composite using the conventional mixing method, because the resistance to matrix expansion was enhanced by the change in microstructure from concentrated particles distribution to dispersed distribution.

The CTE of commercial $\mathrm{Mg}-\mathrm{Al}$ and $\mathrm{Mg}-\mathrm{Al} / \mathrm{AlN}$ composites in the temperature range of $75-450{ }^{\circ} \mathrm{C}$ is represented in Fig. 9b. The CTE showed the same order from top to end as the relative elongation. It can also be seen that the CTE of the $\mathrm{Mg}-\mathrm{Al} / \mathrm{AlN}$ composites was smaller than that of commercial $\mathrm{Mg}-\mathrm{Al}$ alloy at all temperatures. It was evident that the addition of AlN particles lowered the
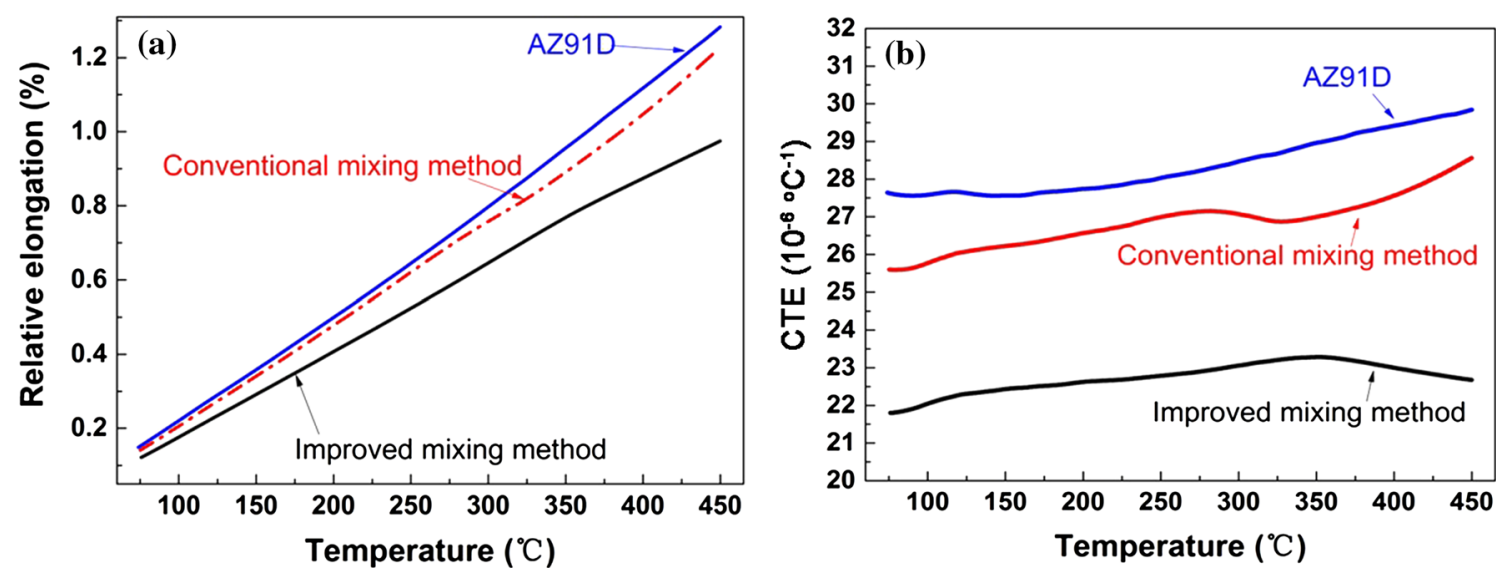

Fig. 9 Temperature dependence of relative elongation a and CTE $\mathbf{b}$ for commercial $\mathrm{Mg}-\mathrm{Al}$ : alloy and $\mathrm{Mg}-\mathrm{Al} / \mathrm{AlN}$ composites using different mixing methods 
coefficient of thermal expansion and enhanced the dimensional stability of the composites.

The CTE of AlN reinforcement $\left(4.5 \times 10^{-6} \mathrm{~K}^{-1}\right)$ was smaller than that of matrix $\mathrm{Mg}\left(26 \times 10^{-6} \mathrm{~K}^{-1}\right)$ [11]. Therefore, the residual thermal stresses were generated in the composites during cooling from the fabrication temperature to room temperature due to CTE mismatch between the matrix and the reinforcement. As a result, the AlN reinforcement bore compressive stress, while the matrix alloy bore tensile stress. The residual thermal stresses resisted the expansion of the matrix alloy during heating [15], resulting in lower CTE of composites than unreinforced commercial $\mathrm{Mg}-\mathrm{Al}$ alloy. In addition, the existence of AlN particles can produce a constraint effect on the expansion of matrix alloy by AlN/matrix interface, due to the lower expansion behavior of the reinforcement. The thermal expansion of the composites would be reduced as the constraint of reinforcement. It also be reported that the thermal expansion of MMCs was influenced by the thermal expansion of the matrix and the restriction or constraint offered by the reinforcement through interfaces $[15,31]$.

Hence, the lower CTE obtained for the $\mathrm{Mg}-\mathrm{Al} / \mathrm{AlN}$ composites relative to the commercial $\mathrm{Mg}-\mathrm{Al}$ alloy could be attributed to the combined effect of existed residual thermal stresses and the constraint of the AlN reinforcement to matrix alloy. The occurrences of the thermal stress and constraint role in composites depended on the reinforcement-matrix interface region, which was crucial for reinforced particle to play a role in decreasing the matrix expansion. The improvement in particle distribution by using the improved mixing method results in more and effective reinforcement-matrix interfaces in the $\mathrm{Mg}-\mathrm{Al} /$ AlN composite. Thus, AlN particles in the composite can provide larger contact area with the matrix and produce higher constraint on the matrix expansion. Then, the role of AlN particles with lower CTE would be enhanced. Therefore, the composite using the improved mixing method showed a smaller CTE.

\section{Conclusions}

The microstructure, thermal diffusivity and thermal expansion of the $\mathrm{Mg}-\mathrm{Al} / \mathrm{AlN}$ composites using different mixing methods were investigated. The main results are given as follows:

1. The intergranular and intragranular distributions of AlN particles were obtained, respectively, by controlling the mixing methods. The composite with intragranular particles exhibited smaller thermal diffusivity value because of the existences of more interfaces, defects and grain boundaries, which acted as scattering centers and reduced the mean free path of electrons and phonons.

2. The $\mathrm{Mg}-\mathrm{Al} / \mathrm{AlN}$ composites showed lower thermal diffusivity than commercial $\mathrm{Mg}-\mathrm{Al}$ alloy, due to the presence of $\mathrm{AlN} / \mathrm{Mg}$ interfaces and the absence of rare earth element $\mathrm{Ce}$.

3. The existence of AlN particles lowered the coefficient of thermal expansion and enhanced the dimensional stability of the composites. And the use of the improved mixing method further reduced the CTE of $\mathrm{Mg}-\mathrm{Al} / \mathrm{AlN}$ composites.

\section{References}

[1] C. Xu, M. Zheng, S. Xu, K. Wu, E. Wang, G. Fan, S. Kamado, Mater. Sci. Eng. A 643, 137 (2015)

[2] L. Zhong, J. Peng, M. Li, Y. Wang, Y. Lu, F. Pan, J. Alloys Compd. 661, 402 (2016)

[3] L. Hou, B. Li, R. Wu, L. Cui, P. Ji, R. Long, J. Zhang, X. Li, A. Dong, B. Sun, J. Mater. Sci. Technol. 33, 947 (2017)

[4] S.S. Zhou, K.K. Deng, J.C. Li, K.B. Nie, F.J. Xu, H.F. Zhou, J.F. Fan, Mater. Des. 64, 177 (2014)

[5] Y. Yao, L. Jiang, G. Fu, L. Chen, Trans. Nonferr. Metal Soc. 25, $2543(2015)$

[6] C. Fang, L. Wang, H. Hao, X. Zhang, J. Mater. Process. Technol. 214, 551 (2014)

[7] J. Chen, C. Bao, Y. Wang, J. Liu, C. Suryanarayana, Acta Metall. Sin. (Engl. Lett.) 28, 1354 (2015)

[8] E. Bedolla, J. Lemus-Ruiz, A. Contreras, Mater. Des. 38, 91 (2012)

[9] S. Sankaranarayanan, M.K. Habibi, S. Jayalakshmi, K.J. Ai, A. Almajid, M. Gupta, Mater. Sci. Technol. 31, 1122 (2015)

[10] G. Cao, H. Choi, J. Oportus, H. Konishi, X. Li, Mater. Sci. Eng. A 494, 127 (2008)

[11] J. Chen, C. Bao, W. Chen, L. Zhang, J. Liu, J. Mater. Sci. Technol. 33, 668 (2017)

[12] S.W. Choi, H.S. Cho, C.S. Kang, S. Kumai, J. Alloys Compd. 647, 1091 (2015)

[13] A. Rudajevová, P. Lukáč, Mater. Sci. Eng. A 397, 16 (2005)

[14] S.W. Choi, H.S. Cho, S. Kumai, J. Alloys Compd. 655, 6 (2016)

[15] W. Uju, I. Oguocha, Mater. Des. 33, 503 (2012)

[16] J. Peng, L. Zhong, Y. Wang, J. Yang, Y. Lu, F. Pan, J. Alloys Compd. 639, 556 (2015)

[17] D.J. Lloyd, Int. Mater. Rev. 39, 1 (1994)

[18] M.J. Tan, X. Zhang, Mater. Sci. Eng. A 244, 80 (1998)

[19] J. Chen, C. Bao, Y. Ma, Z. Chen, J. Alloys Compd. 695, 162 (2017)

[20] C.J. Chen, Q.D. Wang, D.D. Yin, J. Alloys Compd. 487, 560 (2009)

[21] T. Ying, M.Y. Zheng, Z.T. Li, X.G. Qiao, S.W. Xu, J. Alloys Compd. 621, 250 (2015)

[22] J. Chen, C. Bao, F. Chen, Mater. Sci. Eng. A 667, 426 (2016)

[23] F.J. Humphreys, Acta Metall. 25, 1323 (1977)

[24] X.J. Wang, X.S. Hu, K.B. Nie, K.K. Deng, K. Wu, M.Y. Zheng, Mater. Sci. Eng. A 545, 38 (2012)

[25] G. Amirthan, A. Udaya kumar, M. Balasubramanian, Ceram. Int. 37, 423 (2011) 
[26] E.S. Toberer, L.L. Baranowski, C. Dames, Ann. Rev. Mater. Res. 42, 179 (2012)

[27] R.J. Bruls, H.T. Hintzen, R. Metselaar, J. Eur. Ceram. Soc. 25, 767 (2005)

[28] L.G. Hou, R.Z. Wu, X.D. Wang, J.H. Zhang, M.L. Zhang, A.P. Dong, B.D. Sun, J. Alloys Compd. 695, 2820 (2017)
[29] T. Ying, M.Y. Zheng, Z.T. Li, X.G. Qiao, J. Alloys Compd. 608, 19 (2014)

[30] C. Suryanarayana, Prog. Mater Sci. 46, 1 (2001)

[31] S. Kúdela, A. Rudajevová, Mater. Sci. Eng. A 462, 239 (2007) 